\title{
Asmanex Twisthaler: approved in USA for once-daily initiation and maintenance treatment of asthma in children
}

\author{
Barbara P. Yawn, MD MSC FAAFP \\ Director of Research, Olmsted Medical Center, Rochester, MN USA
}

Drugs in Context

DOI: http://dx.doi.org/10.1371/journal.dic.212222

Citation: Yawn, B. Asmanex Twisthaler: approved in USA for once-daily initiation and maintenance treatment of asthma in children. Drugs in Context: e212222. doi:10.7573/dic.212222

Copyright: this is an open access article published under the terms of the Creative Commons License Deed (CG BY-NC-ND 3.0) which allows you to share, copy, distribute and transmit the work provided it is properly attributed. You may not use this work for commercial purposes. For further information on commercial use, contact publisher@justmedicalmedia.com or go to wrerw.drugsincontext.com/copyright.

NB: This article was originally published by CSF Medical Communications Ltd (CSF) in Drugs in Context 2008;4(2):173-6. Drugs in Context and all CSF copyrights were acquired by Just Medical Media Ltd in 2009. 


\title{
Asmanex Twisthaler: approved in USA for once-daily initiation and maintenance treatment of asthma in children
}

\author{
Barbara P. Yawn, MD MSC FAAFP \\ Director of Research, Olmsted Medical Center, Rochester, MN USA
}

\section{WHY IS THIS AN ADVANCE?}

Asthma is very common in children ages 4 to 11 years. ${ }^{\text {TT }}$ This is a period in life where administering medications may also be met with several barriers including the child's refusal to take medication, the time pressures of school and parental work and the need for simple medication regimens. ${ }^{2}$ Mometasone is the only inhaled corticosteroid (ICS) recommended for once-daily use when initiating or maintaining ICS therapy for child ages 4 to 11 years. All other ICS therapies are designed to be started with twice daily doses. Having a simple once a day regimen given in the evening makes Asmanex unique among ICS therapies.

The expansion of the FDA licensure for mometasone from ages 12 and above to ages 4 and older, comes with the approval of a new dosage strength, $110 \mathrm{mg}$ per inhalation that delivers the equivalent of $100 \mathrm{mg}$ of the steroid. ${ }^{3,4,5}$ The approval expands the physician's ability to use once daily ICS therapy in all school-aged children.

Mometasone is delivered via the Twisthaler which provides another inhaler device choice for children. The dry powder device comes with a counter integrated into the inhaler making it easier to remember when to replace the old inhaler. The Twisthaler is breath actuated allowing the child to decide when to inhale, easing concerns about coordinating inhaling and triggering the device.

\section{REVIEW OF THE APPROVAL STUDIES}

Four studies were provided to the FDA for approval purposes, three 12- week studies that included 360 children and one 52-week safety trial of 152 children. To date these studies remain unpublished. ${ }^{6}$ The 12 week placebo-controlled studies compared various doses of mometasone from $110 \mathrm{mcg}$ given either morning or night, 110 mcg given twice a day and $220 \mathrm{mcg}$ given in the morning. In the largest of the studies, 98 children were treated with Asmanex Twisthaler $110 \mathrm{mcg}$ once daily in the evening and their outcomes were compared to 99 children treated with placebo for the same 12 weeks. The primary outcome was the change in morning pre-dose $\mathrm{FEV}_{1}$ in percent-predicted. Improvement was statistically significantly better with the once in the evening Asmanex $(110 \mathrm{mcg})$ compared to placebo, $(4.73$ versus -1.77$)$. Figure 1 displays the results for $\%$ predicted $\mathrm{FEV}_{1}$ change from baseline at endpoint. Secondary endpoints of morning and evening peak expiratory flow were higher and use of rescue medication was lower for those children treated with Asmanex versus placebo.

In the long-term active-controlled safety trial $(n=152)$, patients with asthma (4 to 11 years of age, $60 \%$ males and $40 \%$ females, $84 \%$ Caucasian, $11 \%$ Black and 5\% Hispanic) received Asmanex Twisthaler $110 \mathrm{mcg}$ twice daily or $220 \mathrm{mcg}$ once daily in the morning for 12 weeks (Table 1). Overall adverse affects were no different in the Asmanex versus placebo group. 
Figure 1. A 12-week trial in children 4-11 years of age: \% predicted $\mathrm{FEV}_{1}$ change from baseline over time and at endpoint by treatment group

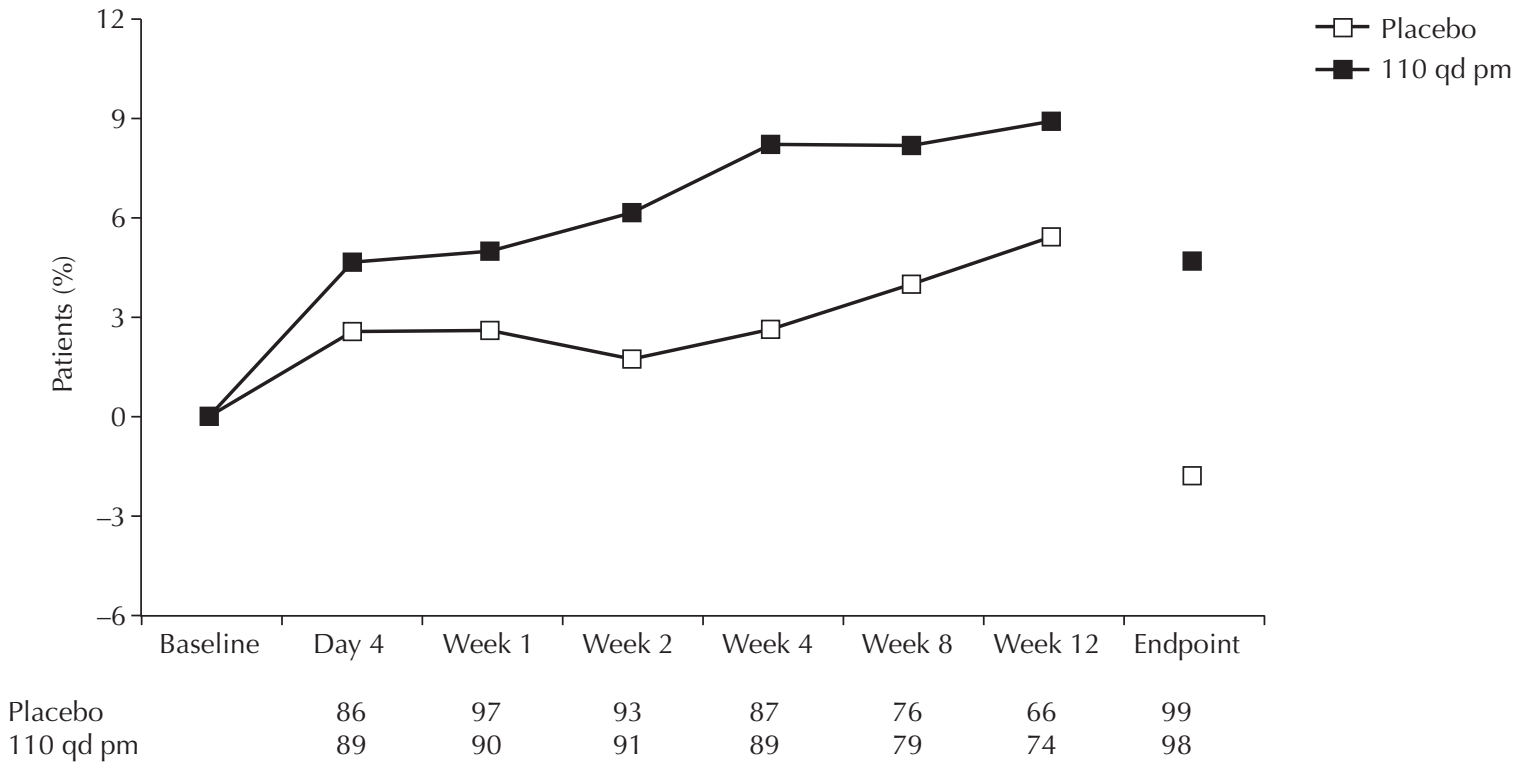

Note: Endpoint $=$ last available data for each subject

Table 1: Adverse reactions with $\geq 2 \%$ incidence in a 12-week clinical trial with Asmanex Twisthaler in patients 4 to 11 years of age previously on bronchodilators and/or inhaled corticosteroids

\begin{tabular}{|c|c|c|}
\hline \multirow{3}{*}{ Adverse Reaction } & \multicolumn{2}{|l|}{$(\%)$ of Patients } \\
\hline & \multicolumn{2}{|c|}{ Asmanex Twisthaler } \\
\hline & $\begin{array}{l}110 \text { mcg } \\
\text { illy in the evening }\end{array}$ & $\begin{array}{c}\text { Placebo } \\
(n=99)\end{array}$ \\
\hline \multicolumn{3}{|c|}{$(n=98)$} \\
\hline Fever & 7 & 5 \\
\hline Allergic rhinitis & 4 & 3 \\
\hline Abdominal pain & 6 & 2 \\
\hline Vomiting & 3 & 2 \\
\hline Urinary tract infection & 2 & 1 \\
\hline Bruise & 2 & 0 \\
\hline Average duration of exposure (days) & 72 & 68 \\
\hline
\end{tabular}

\section{Mechanism of action}

Mometasone furoate is a corticosteroid demonstrating potent anti-inflammatory activity. Despite recommendations of ICS for treatment of asthma, the precise mechanism of corticosteroid action on asthma is not known. In vitro studies suggest that on a per weight basis, mometasone is more potent than other glucocorticoid: 12 times that of dexamethasone, 7 times that of triamcinolone acetonide, 5 times that of budesonide, and 1.5 times that of fluticasone. The clinical significance of these findings is unknown. ${ }^{6,7}$

\section{Administration}

A demonstration of this device is strongly recommended before sending the parent and child off with a new prescription. Hopefully the pharmacist will demonstrate the inhaler technique for the family. The following instructions come directly from the package insert which needs to be read carefully. ${ }^{6}$

- Remove the Asmanex Twisthaler from its foil pouch and write the date on the cap label.

- Throw away the inhaler 45 days after this date or when the dose counter reads "00", whichever comes first.

- Follow steps to open inhaler and inhale dose each time you inhale a dose from your Asmanex Twisthaler. 
The inhaler should be stored in a clean dry site which probably excludes a bathroom that gets humid during showers or baths. The inhaler can be kept in a cool or even cold place since it is safe to $-89^{\circ} \mathrm{F}$.

\section{CLINICAL USE AND IMPACT}

World estimates of the prevalence of asthma in school aged children vary from $3 \%$ to over $20 \% .^{1}$ ICS monotherapy is considered the initial medication of choice in children with mild and moderate persistent asthma and to be used for maintenance therapy for all children who can be controlled using ICS alone. ${ }^{8}$ This is estimated to be between 20 and $40 \%$ of all children with asthma. ${ }^{9,10}$ Unfortunately, ICS therapy is underprescribed for children in the U.S. ${ }^{11,12,13}$ Therefore, the size of the population that might benefit from any ICS is estimated in the millions. Although Asmanex for children 4 to 11 years of age is being introduced to a very full market, it is the first ICS that is recommended to be started once a day. ${ }^{14}$ Currently many children who are candidates for ICS are not receiving them. ${ }^{9,16}$ For some parents and families the idea of a once a day medication may be sufficiently appealing to increase initiation and perhaps to enhance adherence. As with all medications cost considerations are critical, especially for people without drug coverage or with large co-pays. Generic ICS is available but not often used. If the Asmanex co-pay or deductible is similar to that of other brand name ICS medications its addition does provide an important choice. Mometasone has also been shown to help in reducing the need for oral steroids and to have equivalent or better efficacy than other commonly used steroids in cases of severe asthma. ${ }^{7,16,17}$ Asmanex can be combined with a long acting beta agonist (using separate inhalers) to treat those with severe or more difficult to control asthma. ${ }^{17}$

The challenge for any practice is learning how to use and teach inhaler technique for another inhaler. However, many nurses, medical assistants and physicians do not know how to demonstrate metered dose inhaler use and those have been available for decades. For an audio and visual demonstration of the Twisthaler, type 'Twisthaler' into google.com and click on 'Demo'. The speed of inhalation is not a concern for even young chldren with the Twisthaler. Studies show that inhalation rates as low as $28 \mathrm{l} /$ min (about 1/10 the usual speed of inhalation in a child) can trigger the Twisthaler. ${ }^{6}$

The Asmanex Twisthaler cannot cure steroid phobia in either health professionals or parents. ${ }^{2,11,16}$ But the safety data for Asmanex are excellent in children and adults. ${ }^{5,7}$ The fears of slowed growth with the use of any ICS must always be compared to the risks of having uncontrolled asthma, together with impaired ability to participate in normal childhood activities and development. ${ }^{18}$ In low to medium dose ICS, the ICS controlled asthma will always win. ${ }^{9}$

The recommended dose of Asmanex is 110 mcg once daily for all children ages 4 through 11 years. The dose is recommended to be given in the evening from $4 \mathrm{pm}$ to bedtime. Unlike the doses for adolescents, no higher doses are recommended for more severe asthma or for children being weaned from oral steroids. While a single dosage schedule is convenient, in practice you may have to consider things such as the size and weight of the child. An 11 year old girl may have already experienced menarche and a significant grow spurt. A 4-year-old boy or girl may be less than 4 feet tall and weigh less than 50 pounds while a 10 or 11 year old may be over 5 feet tall and weigh more than 100 pounds. Using a single dose across these age ranges may not provide the control required and so clinical judgment will be required.

The Asmanex Twisthaler for children 4 to 11 years of age provides a once a day choice using the most effective asthma anti-inflammatory medication currently available - an ICS. 


\section{REFERENCES}

1. Pearce N, Ait-Khaled N, Beasley R, et al. Worldwide trends in the prevalence of asthma symptoms: phase III of the International Study of Asthma and Allergies in Childhood (ISAAC). Thorax 2007; 62: 758-66

2. Orrell-Valente JK, Jarlsberg LG, Rait MA, et al. Parents' specific concerns about daily asthma medications for children.f Asthma 2007; 44: 385-90

3. Bernstein DI, Berkowitz RB, Chervinsky P, et al. Doseranging study of a new steroid for asthma: mometasone furoate dry powder inhaler. Respir Med 1999; 93: 603-12

4. Inman MD, Watson RM, Rerecich T, et al. Dose-dependent effects of inhaled mometasone furoate on airway function and inflammation after allergen inhalation challenge. Am 7 Respir Crit Care Med 2001; 164: 569-74

5. O'Connor B, Bonnaud G, Haahtela T, et al. Dose-ranging study of mometasone furoate dry powder inhaler in the treatment of moderate persistent asthma using fluticasone propionate as an active comparator. Ann Allergy Asthma Immunol 2001; 86: 397-404

6. Schering-Plough. Asmanex prescribing information 2007.

7. Bousquet J, D'Urzo A, Hebert J, et al. Comparison of the efficacy and safety of mometasone furoate dry powder inhaler to budesonide Turbuhaler. Eur Respir 7 2000; 16: 808-16

8. NAEPP 2007 guidelines.

9. Fuhlbrigge AL, Guilbert T, Spahn J, et al. The influence of variation in type and pattern of symptoms on assessment in pediatric asthma. Pediatrics 2006; 118: 619-25

10. Stempel DA, McLaughin TP, Stanford RH, et al. Patterns of asthma control: a 3-year analysis of patient claims. f Allergy Clin Immunol 2005; 115: 935-9
11. Cabana MD, Abu-Isa H, Thyne SM, Yawn B. Specialty differences in prescribing inhaled corticosteroids for children. Clin Pediatr (Phila) 2007; 46: 698-705

12. Adams RJ, Fuhlbrigge A, Finkelstein JA, et al. Impact of inhaled antiinflammatory therapy on hospitalization and emergency department visits for children with asthma. Pediatrics 2001 ; 107: 706-11

13 Adams RJ, Fuhlbrigge A, Guilbert T, et al. Inadequate use of asthma medication in the United States: results of the asthma in America national population survey. 7 Allergy Clin Immunol 2002; 110: 58-64

14. Kemp JP, Berkowitz RB, Miller SD, et al. Mometasone furoate administered once daily is as effective as twice-daily administration for treatment of mild-to-moderate persistent asthma. F Allergy Clin Immunol 2000; 106: 485-92

15. Nathan RA, Nayak AS, Graft DF, et al. Mometasone furoate: efficacy and safety in moderate asthma compared with beclomethasone dipropionate.Ann Allergy Asthma Immunol 2001; 86: 203-10

16. Cabana MD, Lara M, Shannon J. Racial and ethnic disparities in the quality of asthma care. Chest 2007; 132(Suppl):810S-817S

17. Fish JE, Karpel JP, Craig TJ, et al. Inhaled mometasone furoate reduces oral prednisone requirements while improving respiratory function and health-related quality of life in patients with severe persistent asthma. 7 Allergy Clin Immunol 2000; 106: 852-60

18. Yawn BP, Brenneman SK, Allen-Ramey FG, et al. Assessment of asthma severity and asthma control in children. Pediatrics 2006; 118: 322-9 